\title{
TORTA DE MAMONA NO CONTROLE DA BROCA-DO-RIZOMA (Cosmopolites sordidus) EM BANANEIRA-TERRA ${ }^{1}$
}

\author{
LEILA CRISTINA ROSA DE LINS², MARILENE FANCELLI ${ }^{3}$, \\ CECÍLIA HELENA SILVINO PRATA RITZINGER ${ }^{3}$, MAURÍCIO ANTONIO COELHO FILHO ${ }^{3}$, \\ CARLOS ALBERTO DA SILVA LEDO 3
}

RESUMO - Objetivou-se avaliar o efeito da torta de mamona sobre a infestação por Cosmopolites sordidus e o desenvolvimento de mudas de bananeira cultivar Terra. Avaliaram-se diferentes dosagens da torta de mamona ( $0 \mathrm{~g}, 12 \mathrm{~g}, 15 \mathrm{~g}, 18 \mathrm{~g} \mathrm{e} 24 \mathrm{~g})$ aplicadas a cada dois meses, a partir do plantio em mudas de bananeira dispostas num delineamento inteiramente casualizado, com dez repetições. Avaliou-se a evolução vegetativa das mudas pela altura da planta, pelo diâmetro do pseudocaule e pelo número de folhas verdes. Efetuou-se a infestação das plantas com 25 adultos de C. sordidus em cada muda. Os danos causados foram avaliados por meio da percentagem de galerias no rizoma, número de adultos vivos e mortos, número de larvas e número de pupas. Determinou-se também o efeito dos tratamentos sobre o valor de absorbância relativo ao teor de clorofila nas folhas por meio do uso de um clorofilômetro. Observou-se baixa infestação da broca-do-rizoma nas mudas tratadas com a torta de mamona. $\mathrm{O}$ crescimento e a absorbância foram afetados positivamente pela aplicação da torta de mamona. Assim, a torta de mamona reduz a população de $C$. sordidus nos rizomas de bananeira cv. Terra, favorece o crescimento das plantas e aumenta o valor de absorbância.

Termos para indexação: Musa sp., Ricinus communis, manejo orgânico.

\section{CASTOR BEAN PIE ON THE CONTROL OF BANANA WEEVIL BORER (Cosmopolites sordidus) IN BANANA 'TERRA'}

\begin{abstract}
The aim of this study was to evaluate the effects of castor bean pie on the infestation by Cosmopolites sordidus and on the development of banana plants cv. Terra. To observe the dose-response relationship, each treatment focused on a different dosage of castor bean pie $(0 \mathrm{~g}, 12 \mathrm{~g}, 15 \mathrm{~g}, 18 \mathrm{~g}, 24 \mathrm{~g})$ applied every two months to the banana plants, starting from the planting date. The experimental design was completely randomized with ten replicates. Plant vegetative growth was evaluated by measuring plant height, pseudostem diameter, and counting alive (or green) leaves. The infestation of plants was undertaken by using 25 adults of $C$. sordidus per plant. Six months after planting, the percentage of damage caused was scored on rhizomes and the number of adults (alive and died), larvae, and pupae was registered. Absorbance related to the leaf chlorophyll content was also determined by a chorophyllometer. In plants treated with castor bean pie there was a low infestation of the banana weevil borer. Vegetative growth and absorbance were also positively affected by applying castor bean pie. Therefore, castor bean pie reduces C. sordidus population in rhizomes of bananas cv. Terra, improving vegetative growth and chlorophyll content in leaves. Index terms: Musa sp., Ricinus communis, organic management.
\end{abstract}

\footnotetext{
1'(Trabalho 052-13). Recebido em: 17-01-2013. Aceito para publicação em: 19-04-2013.

${ }^{2}$ Aluna de Doutorado do Departamento de Fitotecnia da Universidade Federal de Viçosa, CEP 36.570-000, Viçosa/MG - Brasil. E-mail: leila.lins@ufv.br

${ }^{3}$ Pesquisador(a) Embrapa Mandioca e Fruticultura, C.P.007, CEP 44.380-000, Cruz das Almas/BA-Brasil. E-mails: fmarilene.fancelli@embrapa.br; cecilia.ritzinger@embrapa.br; mauricio-antonio.coelho@embrapa.br; carlos.ledo@embrapa.br
} 


\section{INTRODUÇÃO}

A banana é um dos frutos mais produzidos e consumidos em todo o mundo, com uma produção mundial de aproximadamente 99,0 milhões de toneladas em 2009 (RIBEIRO, 2012). A produção brasileira de banana coloca o País como quinto maior produtor mundial, com a produção, em 2012, de 6,833 milhões de toneladas e área plantada de 520.766 ha, sendo São Paulo, Bahia, Santa Catarina, Minas Gerais e Pará os cinco principais produtores nacionais, (LICHTEMBERG, et al., 2011), respectivamente (IBGE, 2012).

As bananeiras tipo Terra, muito suscetíveis ao ataque da broca-do-rizoma, são cultivadas principalmente nas regiões Norte e Nordeste, onde muitas vezes os solos são pobres em nutrientes, e a falta de estudos e de informações sobre essas cultivares leva à prática de manejo sem técnicas adequadas Os principais problemas enfrentados pelos produtores, além da comercialização, são a alta incidência da broca-do-rizoma (Cosmopolites sordidus), o manejo da planta e as técnicas de adubação (BORGES et al., 2002).

A broca-do-rizoma, Cosmopolites sordidus (Germar), principal praga dos bananais, destaca-se por provocar elevados prejuízos à produção e pela distribuição em praticamente todas as áreas onde se cultiva banana (SILVA; FANCELLI, 1998; MESQUITA; ALVES, 1983). Os inseticidas usualmente empregados no controle da broca-do-rizoma vêm sofrendo sérias objeções, além de serem utilizados com restrição na Produção Integrada (PI), e inadmissíveis na produção orgânica.

A importância do equilíbrio nutricional durante todo o ciclo da banana é fundamental para se obter altas produtividades, sendo a adubação orgânica de grande importância, pois além de melhorar as propriedades físicas e biológicas do solo, é também a melhor forma de fornecer nitrogênio no plantio (NOMURA et al., 2009). Além disso, Lins et al. (2008) apontaram a adubação equilibrada como sendo um dos fatores que contribui para a baixa infestação da broca-do-rizoma na cultura da bananeira.

A aplicação de matéria orgânica pode promover benefício às plantas com relação à sua nutrição, bem como favorecer a manutenção de umidade, diminuindo o estresse hídrico (RITZINGER; FANCELLI, 2006). A utilização de substratos orgânicos com características adequadas à espécie plantada possibilita redução do tempo de cultivo e do consumo de insumos, como fertilizantes químicos, defensivos e mão de obra. Independentemente dos efeitos sobre parasitas, as alterações orgânicas proporcionam benefícios importantes, especialmente na melhoria da fertilidade e da estrutura do solo (MCSORLEY, 2011).

Estratégias de baixo impacto ambiental na adubação, bem como no controle de pragas, devem ser privilegiadas no manejo da cultura. Entretanto, trabalhos com produtos alternativos utilizados com este objetivo na cultura da bananeira são escassos na literatura. $\mathrm{O}$ emprego de agentes biológicos entomopatogênicos, a exemplo do fungo Beauveria bassiana (DALZOTO; UHRY, 2009) e dos nematoides Steinernema carpocapsae e Heterorhabditis bacteriophora (SEPULVEDA-CANO et al., 2008), tem sido estudado como formas eficientes de controle da broca-do-rizoma na perspectiva alternativa aos produtos químicos convencionalmente usados.

A torta de mamona é um dos principais resíduos do beneficiamento e industrialização da mamona, resultante da extração do óleo, e tem sido citada na literatura como adubo orgânico e como matéria-prima para compor substratos na própria cultura da mamoneira, principalmente por apresentar relação $\mathrm{C} / \mathrm{N}$ de 11:1, com elevado teor de nitrogênio (LIMA et al., 2006; MARTINS et al., 2011).

Solos que recebem torta de mamona apresentam atividade microbiana maior quando comparados com solos que recebem esterco bovino ou bagaço de cana. A mineralização da torta de mamona ocorre de forma intensa, sendo que seus nutrientes são rapidamente liberados e disponibilizados para as plantas (SEVERINO et al., 2004). Dessa forma, a torta de mamona representa um aporte de nutrientes às plantas além de possuir ação complementar como nematicida (RITZINGER; FANCELLI, 2006.).

O objetivo deste trabalho foi verificar se a torta de mamona teria também efeito sobre a infestação pela broca-do-rizoma (C. sordidus) e ao mesmo tempo favorecer o desenvolvimento de mudas de bananeira cultivar Terra.

\section{MATERIAL E MÉTODOS}

O experimento foi conduzido no período de janeiro a julho de 2008, em campo da Embrapa Mandioca e Fruticultura, no município de Cruz das Almas, Bahia, situado a $12^{\circ} 40^{\prime} 19^{\prime \prime}$ de latitude sul e $39^{\circ} 06^{\prime} 22^{\prime}$ ' de longitude oeste de Greenwich. A altitude é de 220 $\mathrm{m}$ acima do nível do mar, com pluviosidade média anual de $1.170 \mathrm{~mm}$ e temperatura média de $24,5^{\circ} \mathrm{C}$.

Foram obtidas mudas padronizadas do tipo chifrinho de bananeira cv. Terra oriundas do pomar experimental da Embrapa Mandioca e Fruticultura, as quais foram plantadas em sacos de $15 \mathrm{~kg}$ contendo solo como substrato. Foram utilizadas 50 mudas, mantidas a pleno sol e irrigadas diariamente. 
As aplicações da torta de mamona foram iniciadas dois meses após o plantio e repetidas a cada dois meses. Utilizaram-se as seguintes dosagens: $0 \mathrm{~g}$, $12 \mathrm{~g}, 15 \mathrm{~g}, 18 \mathrm{~g} \mathrm{e} 24 \mathrm{~g}$. A torta de mamona foi aplicada em torno das mudas, próximo do pseudocaule. $\mathrm{O}$ experimento foi disposto no delineamento inteiramente casualizado, com 10 repetições por tratamento.

Quatro meses após o plantio, com duas aplicações da torta de mamona, as plantas foram infestadas forçadamente com adultos de Cosmopolites sordidus. Foram colocados 25 insetos em cada planta, os quais foram coletados em campo e mantidos em quarentena, pelo período de sete dias antecedente à infestação. As plantas permaneceram isoladas por um pedaço de tubo de PVC ( $20 \mathrm{~cm}$ de diâmetro), que foi mantido durante todo o período experimental. Após a infestação, o tubo de PVC foi recoberto por tela para evitar a fuga dos insetos introduzidos e a entrada de outros insetos.

Quinzenalmente, a partir da data do plantio, foram avaliados altura da planta e o diâmetro do pseudocaule a $10 \mathrm{~cm}$ do solo e número de folhas verdes. Dois meses após a infestação, quando as plantas apresentavam seis meses de idade, foi feita a avaliação de danos causados por $C$. sordidus.

Os danos na periferia do rizoma foram avaliados após a remoção do solo e das raízes ao redor do mesmo, mediante cortes superficiais no rizoma, expondo as galerias feitas pelo inseto. Também foi feita a avaliação de galerias, cortando-se transversalmente o rizoma na altura de seu perímetro máximo, dividindo-se a área em quatro partes e avaliando-se visualmente os danos causados pela broca em cada parte, sendo a porcentagem de danos dada pela soma dos quatro valores. Além disso, foi feita a contagem do número de adultos vivos e mortos, do número de larvas e do número de pupas presentes nas plantas. Ao final do experimento, determinou-se também o efeito dos tratamentos sobre o valor de absorbância relativo ao teor de clorofila nas folhas, em três posições (borda, meio e centro), por meio de um clorofilômetro, obtendo-se um valor médio entre os três valores observados.

Os dados referentes às porcentagens de galerias, ao número de insetos, ao número de larvas e de pupas foram transformados para $\sqrt{(x+0,5)}$. Foram feitas análises de variância e regressão, utilizando o programa SAEG 9.1 - Sistema para Análises Estatísticas e Genéticas (2007).

\section{RESULTADOS E DISCUSSÃO}

A aplicação da torta de mamona proporcionou aumento vegetativo em todas as características avaliadas (Figuras 1A, 1B e 1C). Para a altura, diâmetro do pseudocaule e número de folhas vivas, as equações de regressão apresentaram ajuste quadrático, indicando que a torta de mamona foi benéfica até certo ponto. A altura máxima foi alcançada na dosagem de $15 \mathrm{~g}$, ponto máximo da curva de regressão $\left(\mathrm{R}^{2}=\right.$ 0,997). Para o diâmetro do pseudocaule, o maior valor encontrado foi de $4,71 \mathrm{~cm}$, quando se utilizaram $12 \mathrm{~g}$ da torta de mamona, ponto máximo da curva de regressão $\left(\mathrm{R}^{2}=0,963\right)$. Houve uma tendência de aumento foliar até a dosagem de $24 \mathrm{~g}$ da torta de mamona. Contudo, no intervalo de aplicação entre $15 \mathrm{a} 24 \mathrm{~g}$ da torta de mamona, o aumento de número de folhas foi pequeno $\left(R^{2}=0,848\right)$.

Há uma tendência de aumento da absorbância (Figura 1D) com o aumento das doses de aplicação da torta de mamona $\left(\mathrm{R}^{2}=0,976\right)$. Conforme Godoy et al. (2007), as leituras efetuadas pelo clorofilômetro correspondem ao teor relativo de clorofila presente na folha da planta, através da avaliação da intensidade da cor verde da folha. Ainda de acordo com esses autores, os valores são calculados pelo clorofilômetro com base na quantidade de luz transmitida pela folha, em dois comprimentos de ondas, com diferentes absorbâncias da clorofila, sendo a correlação entre a leitura do clorofilômetro e os teores de clorofilas presente na folha bastante alta. Sendo assim, considera-se que a aplicação da torta de mamona foi benéfica no sentido de se aumentar a eficiência da clorofila presente na folha.

Não houve adequação de ajuste para número de adultos vivos (Figura 2A). Observou-se que houve tendência de aumento do número de adultos mortos (Figura 2 B) com o aumento da dose fornecida, e dessa forma o maior número de adultos mortos $(4,93)$ encontrados foi quando se utilizou a maior dose da torta de mamona. O número de larvas e pupas apresentaram comportamento semelhante; entretanto, a partir da dose de $15 \mathrm{~g}$, observou-se tendência de redução no número de larvas na medida em que se aumentou a dosagem da torta de mamona aplicada, enquanto para o número de pupas a tendência foi de aumento (Figuras 2C e 2D).

No corte transversal do rizoma, houve redução de $68,8 \%$ das galerias internas ao rizoma, comparando-se a não aplicação com a dosagem máxima fornecida (Figura 2E). Não houve adequação de ajuste para porcentagem de galerias na periferia do rizoma (Figura 2F). Contudo, no controle, observou-se a incidência de $36,47 \%$ de galerias, enquanto na 
dosagem de $24 \mathrm{~g}$, as plantas apresentaram menos danos $(19,50 \%)$.

Os resultados obtidos para o desenvolvimento das plantas discordam daqueles relatados por Lima et al. (2008), que verificaram aumento significativo nos valores de altura, diâmetro caulinar, área foliar e matéria seca total em mudas de mamoneira, de forma proporcional à dose de torta de mamona fornecida.

A redução das galerias feitas pelas larvas, na medida em que se aumentou a dosagem fornecida da torta de mamona, é resultante do aumento da mortalidade dos insetos e consequente redução de sua progênie. A toxicidade, provavelmente, seja responsável por reduzir a população de $C$. sordidus, conforme observado no presente trabalho e reportado por Worbs et al. (2011), além de sugerir maior dificuldade das larvas para penetrar no rizoma.

De acordo com os resultados obtidos, a torta de mamona pode representar uma alternativa interessante para fertilização e também para manejo da broca-do-rizoma, pois não deixa resíduos tóxicos nos frutos, além de apresentar propriedades fertilizantes e nematicidas, conforme mencionado por Fermino e Kampf (2003).
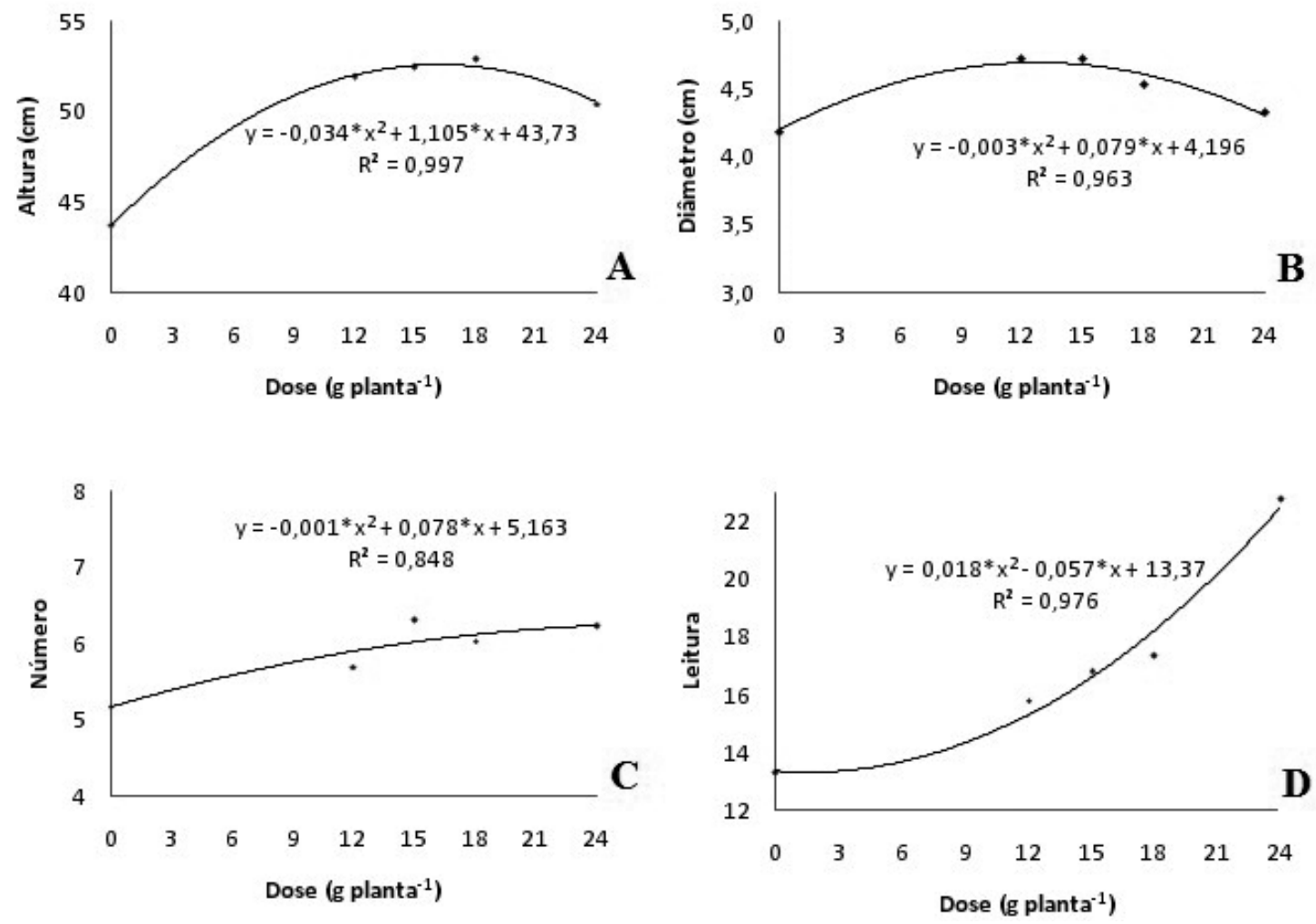

FIGURA 1- Altura das plantas (A), diâmetro do pseudocaule (B), número de folhas vivas (C) e absorbância relativa ao teor de clorofila nas folhas (D), em plantas de bananeira cv. Terra, sob diferentes dosagens de torta de mamona. Cruz das Almas-BA. 

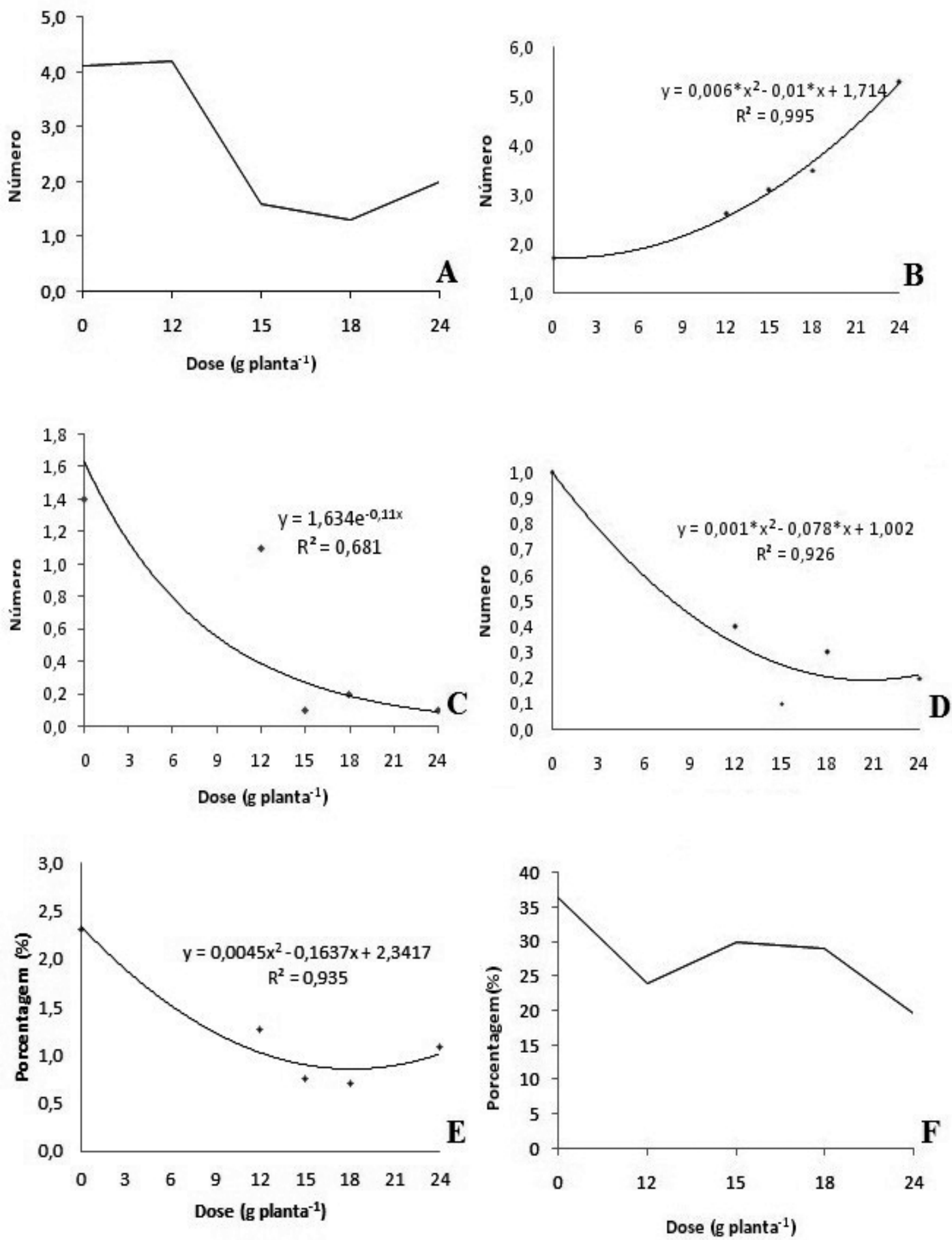

FIGURA 2 -Número de adultos vivos (A); número de adultos mortos (B); número de larvas (C); número de pupas (D); galerias no corte transversal do rizoma (E); galerias na periferia do rizoma $(\mathrm{F})$, em plantas de bananeira cv. Terra, sob diferentes dosagens de torta de mamona. Cruz das Almas-BA. 


\section{CONCLUSÕES}

A torta de mamona reduz a população de Cosmopolites sordidus nos rizomas de bananeira cv. Terra, além de favorecer o crescimento das plantas e aumentar o valor de absorbância, que expressa o teor relativo de clorofila nas folhas.

\section{REFERENCIAS}

BORGES, A.L.; SILVA, T.O.; CALDAS, R.C.; ALMEIDA, I.E. Adubação nitrogenada para bananeira-'terra'(Musa sp. AAB, subgrupo Terra). Revista Brasileira de Fruticultura, Jaboticabal, v. 24, n. 1, p. 189-193, 2002.

DALZOTO, P.R.; UHRY, K.F. Controle biológico de pragas no Brasil por meio de Beauveria bassiana (Bals.) Vuill. Biológico, São Paulo, v. 71, p. 37-41, 2009.

FERMINO, M.H.; KAMPF, A.N. Uso do solo Bom Jesus com condicionadores orgânicos como alternativa de substrato para plantas. Pesquisa Agropecuária Gaúcha, Porto Alegre, v.9, n.1/2, p.33-41, 2003.

GODOY, L.J.G.; SOUTO, L.S.; FERNANDES, D.M.; BÔAS, R.L.V. Uso do clorofilômetro no manejo da adubação nitrogenada para milho em sucessão a pastagem de Brachiaria decumbens. Ciência Rural, Santa Maria, v.37, n.1, p.38-44, 2007.

IBGE. Levantamento sistemático da produção agrícola. 2012. Disponível em: $<$ http://www.sidra. ibge.gov.br/bda/prevsaf/default.asp $>$. Acesso em: 17 dez. 2012.

LICHTEMBERG, L.A.; LICHTEMBERG, P. dos S. F. Avanços na bananicultura brasileira, Revista Brasileira de Fruticultura, Jaboticabal, v. 33, n.1 - edição especial., p. 29-36, 2011.

LIMA, R.L.S.; SEVERINO, L.S.; ALBUQUERQUE, R.C.; BELTRÃO, N.E.M.; SAMPAIO, L.R. Casca e torta de mamona avaliadas em vasos como fertilizantes orgânicos. Revista Caatinga, Mossoró, v. 21, n. 5, p. 102-106, 2008.
LIMA, R. L. S. L.; SEVERINO, L. S.; SILVA, M. I. S.; JERÔNIMO, J. F.; VALE, L. S.; BELTRÃO, N. E. de M. Substratos para produção de mudas de mamoneira compostos por misturas de cinco fontes de matéria orgânica. Ciência e Agrotecnologia, Lavras, v. 30, n. 3, p. 474-479, 2006.

LINS, R.D.; DANTAS, A.V.L.; FANCELLI, M.; CARVALHO, C.A.L.; LEITE, J.B.V. Infestação da broca-do-rizoma em variedades e híbridos de bananeira em Una, Bahia. Magistra, Cruz das Almas, v. 20, p. 105-108, 2008.

MARTINS, A.N.; SUGUINO, E.; DIAS, N.M.S.; PERDONÁ, M.J. Adição de torta de mamona em substratos na aclimatação de mudas micropropagadas de bananeira. Revista Brasileira de Fruticultura Jaboticabal, v.33, n.1, p.198-207, 2011.

MCSORLEY, R. Overview of Organic Amendments for Management of Plant-Parasitic Nematodes, with Case Studies from Florida. Journal of Nematology, Lawrence, v.43, n.2, 2011

MESQUITA, A.L.M.; ALVES, E.J. Aspectos da biologia da broca-do-rizoma em diferentes cultivares de bananeira. Pesquisa Agropecuária Brasileira, Brasília, v.18, n.12, p.1.289-1.292, 1983.

NOMURA, E.S.; LIMA, J.D.; RODRIGUES, D.S.; GARCIA, V.A.; FUZITANI, E.J. Influência do substrato e do tipo de fertilizante na aclimatização de mudas de bananeira 'Prata-Anã'. Ciência e Agrotecnologia, Lavras, v. 33, n. 3, p. 773-779. 2009.

RIBEIRO, L. R.; OLIVEIRA, L. M. de; SILVA, S. de O.; BORGES, A. L. Caracterização física e química de bananas produzidas em sistemas de cultivo convencional e orgânico. Revista Brasileira de Fruticultura, Jaboticabal, v.34, n.3, p. 774-782, 2012.

RITZINGER, C.H.S.P.; FANCELLI, M. Manejo integrado de nematoides na cultura da bananeira. Revista Brasileira de Fruticultura, Jaboticabal, v. 28 , n. 2, p. 331-338. 2006.

SAEG. Sistema para Análises Estatísticas, Versão 9.1. Viçosa: Fundação Arthur Bernardes/UFV, 2007.

SEPULVEDA-CANO, P.A.; LOPEZ-NUNEZ, J.C.; SOTOGIRALDO, A. Effect of two enthomopathogenic nematodes on Cosmopolites sordidus (Coleoptera: Dryphthoridae). Revista Colombiana de Entomologia, Bogotá, v.34, p.62-67, 2008. 
SEVERINO, L.S.; COSTA, F.X.; BELTRÃO, N.E.M.; LUCENA, A.M.A.; GUIMARÃES, M.M.B. Mineralização da torta de mamona, esterco bovino e casca de mamona estimada pela respiração microbiana. Revista de Biologia e Ciência da Terra, v.5, n.1, 2004. Disponível em: $<$ http:// redalyc.uaemex. $\mathrm{mx} / \mathrm{redalyc} / \mathrm{pdf} / 500 / 50050105 . \mathrm{pdf}>$. Acesso em: 6 fev. 2012.

SILVA, S. O. E.; FANCELLI, M. Banana insect pests. Acta Horticulturae, The Hague, n.490, p. 385-393, 1998.
WORBS, S.; KÖHLER, K.; PAULY, D.; AVONDET, M.; SCHAER, M.; DORNER, M. B.; DORNER, B. G. Ricinus communis intoxications in human and veterinary medicine - A Summary of Real Cases. Toxins, Basel, n.3, p. 1.332-1.372, 2011. 